\title{
Obturator Nerve
}

National Cancer Institute

\section{Source}

National Cancer Institute. Obturator Nerve. NCI Thesaurus. Code C75909.

A nerve that arises from the second, third, and fourth lumbar nerves and enters the thigh

through the obturator canal. It is responsible for the sensory innervation of the skin of the medial aspect of the thigh and also responsible for the motor innervation of the adductor muscles of the lower extremity. 